\title{
Customer Perception and Problems towards Ola Services in Smart Cities with Reference to Salem
}

\author{
J. Senthil Velmurugan', R. Shruthi ${ }^{2}$, S. V. Rajkamal ${ }^{3}$ \\ Associate Professor', Periyar Institute of Management Studies (PRIMS), Periyar University, \\ Salem.Email: jsenthilv@rediffmail.com \\ Ph.D Research Scholar ${ }^{2}$, Periyar Institute of Management Studies (PRIMS), Periyar University, \\ Salem \\ Ph.D Research Scholar ${ }^{3}$, Periyar Institute of Management Studies (PRIMS), Periyar University, \\ Salem.
}

\begin{abstract}
:
Smart cities put data and digital technology to work with the goal of improving the quality of life. This study shows the global interference of technology advancement in cab hailing services in smart cities which enables customers to hail taxis through their smart phones, become popular worldwide. To provide a systematic account of the impact of e-hailing applications' wide adoption on the taxi system, this study is made to analyze the customers perception and upcoming improvements about Ola services. This study focuses on customers and the sample of 120 respondents is been collected and analyses is made for the future scope to retain the effective services of OLA.
\end{abstract}

Keywords: Perceptions, Ola strategies, Smart cities, Enhancement techniques.

\section{INTRODUCTION}

India's transport sector is large and diverse.Transport system is the foundation stone of economic infrastructure. Transport system is known as the key symbol of civilization. Due to huge population and the changing life style of people and their progress, people choose luxuries well being and their transportation needs has been sustained on the convenience, speed and safety of the modes. Good transport connections have direct benefits to people, businesses, the environment, and the economy overall. Amongst the available transportation modes, Road transport occupies a primary place in today's world as it provides a reach unparallel by any other contemporary mode of transport. It helps in the development of trade, commerce and industry.Transport system removes the hindrance of place and time. Depending on the city/state, taxis can either be hailed or are hired from taxi-stands. Providing with taxi services helps people. In metropolitan cities taxis need to be hired from taxi and can be hailed on the street. There are additional surcharges for luggage, late-night rides and toll taxes are to be paid by the passenger.

\section{Taxi services in India}

With rapid urbanization and migration of people from rural areas to cities, the geographical area coverage of Indian cities is expanding. Usage of modern accessories helps people to get updated with the available taxi facilities in the market. The middle class population in India rose from 15 million in

(c) AesthetixMS 2019. This Open Access article is published under a Creative Commons Attribution Non-Commercial 4.0 International License (http://creativecommons.org/licenses/by-nc/4.o/), which permits non-commercial re-use, distribution, and reproduction in any medium, provided the original work is properly cited. For citation use the DOI. For commercial re-use, please contact editor@rupkatha.com. 
1991 to16o million and more in 2016. This segment with its increasing disposable income started demanding and has been willing to pay for better services across sectors including private and public transportation. Rapid economic growth coupled with huge infrastructure development, rigorous effort from Ministry of Tourism to project India as travel destination and emergence of Business Process Outsourcing (BPO) industry has given a huge push to the car rental industry in India. Till2010, the point-to-point taxi market in India's big metropolitan cities was completely unorganized.

\section{Taxi services in metropolitan cities}

A metropolitan area combines an urban agglomeration (the contiguous, built-up area) with zones not necessarily urban in character, but closely bound to the center by employment or other commerce. So people migrate within the intra cities so they prefer cab services with gives them comfort and a luxuries journey and seek for quick means of transportation. These outlying zones are sometimes known as a commuter belt, and may extend well beyond the urban zone, to other political entities.

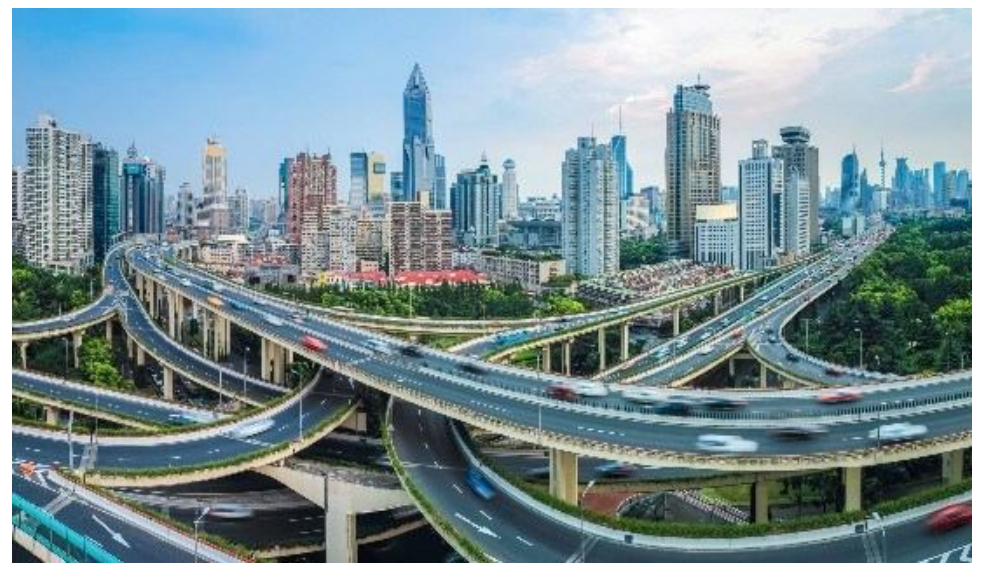

Taxi services in smart cities

Tamil Nadu is the second state to hold largest number of smart cities nominated in the list of smart cities in India. Chennai and Coimbatore secured its place in the first list while Vellore, Madurai, Salem and Thanjavur were selected in the second list in 2016 - 2017.Smart City is a concept of utilizing technologies and connected data sensors to enhance and become powerful in terms of infrastructure and city operations. This includes monitoring and managing of public assets, transportation systems, citizens, power plants, water supplies, information systems, civil bodies, and other community services etc., Among various transportation mode cab service gained popularity because of its advantage of door to door service and now because of technological advancement customers were able to book cabs at competitive price in just one click using their smart phones.These App based cab services were having tremendous potential for growth in densely populated countries like India where parking is major problem because of space crunch as well as public transports are over cowered during peak hours.Thus, this study tries to capture the perspective of customers on the cab hailing services in Salem city and the level of perseverance's to throw some light on the factors which could be a decider for a customer to make his choice among Ola application services available. 


\section{IMPORTANCE OF THE STUDY}

- Among the various options available for consumers in hailing a taxi the researcher wants to identify the reasons and needs why people choose OLA services in particular and their perception towards online app taxi services.Because Ola works hard to build and maintain its customer experience. These are the following reasons the researcher has chosen this study,

Ola has made the highest turnover in last four years.

Ola attracts the customer attention by providing various additional features apart from cab services they have options like Food panda where they take food orders.

They have installed emergency button in their app which when clicked by customer an automotive trigger goes to their rapid response team who takes an immediate report on the incident and resolves it.

$>$ They have tied up with an insurance company to give ride insurance at just rupees 1 per ride.

> They have invented a new category called prime play which gives in cab entertainment helpful for longer rides and when traveling with children.

- Due to the competitive market scenario a detailed study about this helps to analyze about the consumer needs and improvise the future scope. This study will help us to know the customers satisfaction with respect to the comfort, convenience, tariff, service quality and staff courtesy, etc. Also, we can have the input and ideas to improve the services to meet out the customer expectation in the near future.

\section{RESEARCH OBJECTIVES}

- To ascertain the importance of cab services in Smart cities.

- To study the influences of price consciousness of customers while selecting the cab services.

- To ascertain the customers perception towards online app based cab services.

- To know the impact of Ola services in Salem.

- To know the satisfaction level of the customers hailing Ola services.

\section{LITERATUREREVIEW}

$\left(\right.$ Sagar, 2016) ${ }^{1}$ had stated that there was demand for Call-a-Cab service offered by Meru Cab. The cab services are proving security through global positioning system (GPS) and women taxi drivers for women passengers especially during night times.

According to Harding et al (2016) the auto-rickshaws (three wheelers) are more popular in urban transport before the advent of cars and cabs.

(Yeboah, 2015) $)^{2}$ had argued that driver behavior have negative impact on customer satisfaction in Ghana. The variables like continuous service, comfort, reliability and affordability have an impact on customer satisfaction with regard to minicab taxi.

\footnotetext{
${ }^{1}$ Hanif and Sagar (2016). The cab services are proving security through global positioning system (GPS) and women taxi drivers for women passengers especially during night times.
} 
According to $(\mathrm{al}, 2015)^{3}$ the self- service mobile technologies helps the commuters to access lot of data about cab services and such technologies had changed the role of both customers and companies. The adoption of call taxi app (CTA) is impacted perceived usefulness, perceived ease of use, subjective norms and perceived playfulness (Peng, Wang,

$(\mathrm{He}, 2014)^{4}$. Chen (2014) had explained that mobile apps help both drivers and passengers to find each other. At present the mobile apps are helps the customers to find cabs. In the recent years the car rental industry is growing constantly especially in metropolitan cities in India (Rahman, 2014).

Geeta Kesavaraj (2013), reveals that "As global competition grows,communication and technology channels open up new markets, andproducts and services are translated into a wide array of choices for ouraudiences, companies must work harder than ever to gain and keepCustomersat a competitive cost.

$(\mathrm{A},(2016)))^{5}$ states that "Call taxi have a greater value in the community,in the taxi industry is regulated in various ways by the state Governments through their respective Departments of Transport. Through this regulation the Government is able to exert some control over the activities of the industry, with the ultimate objective of providing a higher level of service (a complex construct in itself) to the public.

Ruchi Shukla, Ashish Chandra E Himanshi Jain $\left(2017^{6}\right)$ states that "Every other day in India, there is a new start up offering efficient cab service to the citizens operating in urban and rural lifestyles. This raises a question that is India going through a possible 'Taxi Revolution'

\section{ABOUT OLA:}

Founded in 2011 by Bhavish Aggarwal and Ankit Bhati, Ola is one of the world's largest ridesharing companies. Ola integrates city transportation for customers and driver-partners onto a mobile technology platform ensuring convenient, transparent, and quick service fulfilment. Ola is focused on leveraging the best of technology and building innovative solutions groundup,that are relevant at global scale.

Notably, in 2016, Ola Play the world's first connected car platform for ride-sharing was launched, transforming commuting experiences and setting the tone for global innovation in this space. Beyond offering a highly personal experience for users during their rides, Ola Play also allows its partners like Microsoft, Apple Music, Sony Liv amongst others, to build a high quality interactive and productive experience for its users. Using the Ola mobile app, users across $110+$ cities, can connect with over 1,000,00o driver-partners across cabs, auto-rickshaws, and taxis. Ola has many competitors and the utmost competitor is UBER.Driven by a hyper local approach, Ola is committed to its mission of building mobility for a billion people. Ola provides various additional services like online food orders(Food Panda), cash wallet, etc which promotes customers attention towards Ola application.

\footnotetext{
${ }^{2}$ Horsu and Yeboah (2015), has argued that driver behavior has negative impact on the cab services at Ghana.

${ }^{3} \mathrm{Lu}$ et al (2015), adoption of call taxi app (CTA) is impacted perceived usefulness, perceived ease of use, subjective norms and perceived playfulness.

${ }^{4} \mathrm{He}, 2014$ ), had explained that mobile apps help both drivers and passengers to find each other

${ }^{5}$ Rexi A. 2016, explained about the various departments of transportation

${ }^{6}$ (Jain, 2017) states about the taxi services in urban and rural areas
} 


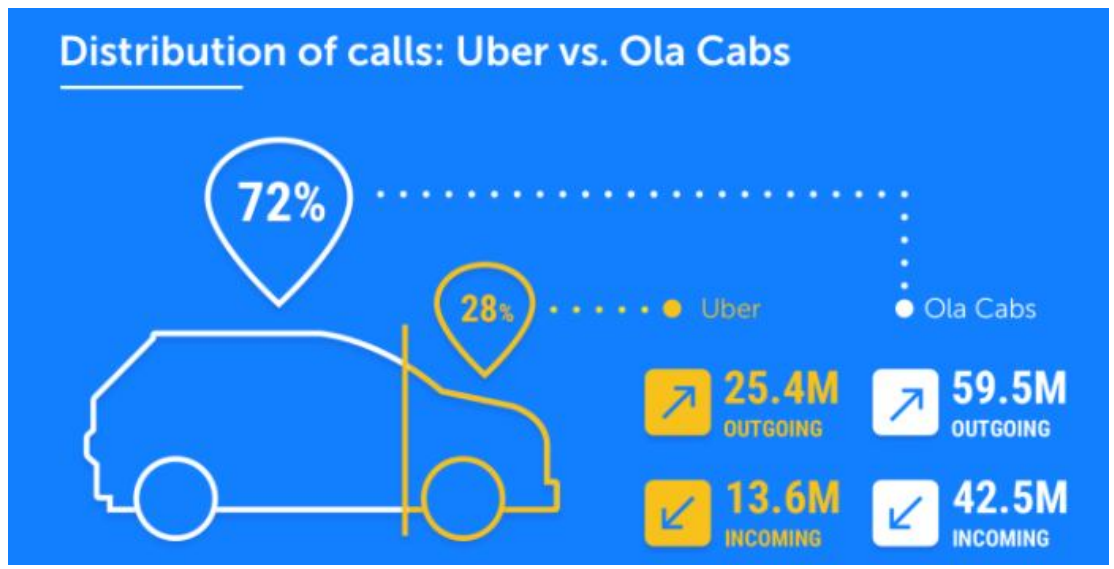

Source: Truecaller

\section{MOTIVES OF OLA SERVICES}

PROMOTIONAL AND MARKETING STRATEGY OF OLA: Ola did many services which convinced people to choose Ola services. Some of them are discussed below.

ENCOURAGING DRIVERS: They offered micro entrepreneurship for the drivers by helping the drivers buy their own cars at huge discounts and affordable repayment scheme as they collaborated with leading car manufacturers.

STRATEGIC PARTNERS WITH MAKE MY TRIP: In the year 2013, Ola cabs launched its partnership with make my trip.

SATISFACTORY SERVICES TO CUSTOMERS: Customer is at the centre in marketing. The purpose of commercial ads and promotional services is to build customer loyalty.

OLA's SOCIAL SERVICE (Boats): During Chennai floods when people were stuck in their offices or other areas Ola had launched its ferry service. Ola had developed this service so as to help stranded people reach home and also to deliver essential material including food, water, etc. The ferries had professional rowers. Each ferry could accommodate 5 to 9 people per trip. They provided three days services day and night and later as per the demand of the people.

\section{CHALLENGES AND PROBLEMS FACED BY CUSTOMERS AND DRIVERS USING OLA APPLICATION \\ DRIVER PROBLEMS}

- Application Usage Training - Unintentional common mistakes include cancelling a ride even before it started, trouble understanding map directions / customer's location, etc. This leads to a bad customer experience.

- Multiple Affiliations - Many drivers are affiliated to both Ola and Uber. They keep searching for customers on both applications.

- Unethical Extra Charges - Drivers especially at night demand extra cash apart from the fare computed by the App. 


\section{TECHNOLOGICAL CHALLENGES:}

- Maps -You have to make multiple phone calls and often show directions (especially to new drivers) to reach your destination

- Data Charges - Most of the Indians still uses 2G. WiFi services are unavailable on roads and data services are very expensive in India.

- $\quad$ Protection against Fraud - Tech savvy customers are coming up with innovative ways to earn free rides.

\section{CUSTOMERPROBLEMS}

\section{POLICY PROBLEMS:}

- Wrong Incentives - Driver's share often depends on the number of rides completed rather than the total revenue generated. This encourages drivers to undertake shorter trips but leads to a downfall in customer's satisfaction level.

- Cab Pooling - Pooling has started very recently in India and is still not available in many cities.

- Customer Service -When feedback is given against driver proper actions need to be taken, based on the rating given adequate actions needs to be taken.

- $\quad$ Free Calls - Ola should provide riders with a feature to connect with drivers for free. Each trip will require just 1 to 2 calls on average.

- Driver Ratings - Currently there is no mechanism to book a cab only with drivers whose rating $>=\mathrm{X}$ (rated by at least 10 different rider)

\section{Research Methodology}

Research can be defined as the search for knowledge or any systematic investigation to establish facts. The primary purpose of Descriptive research is to provide an accurate description or picture of the status or characteristics of a situation or phenomenon and hence the same is adopted in this study.

The Convenience sampling method is followed in-order to collect the data through the structured questionnaire from the respondents (ref.annexure). The sample size so arrived at is 120 respondents forming part of customers of Ola taxi service in Salem.

Data collection method: Both primary and secondary data is been employed.

Tools used: Simple

Percentage method, HenryGarett

Ranking 


\section{DATA ANALYSIS AND INTERPRETATION:}

\section{SIMPLE PERCENTAGE METHOD}

\begin{tabular}{|c|c|c|}
\hline Gender & $\begin{array}{c}\text { No. of } \\
\text { Respondents }\end{array}$ & $\%$ \\
\hline Male & 69 & 46 \\
\hline Female & 51 & 54 \\
\hline Total & 120 & 100 \\
\hline \multicolumn{3}{|l|}{ Agegroup } \\
\hline $0-20$ & 15 & 12.5 \\
\hline $21-30$ & 52 & 43.33 \\
\hline $31-40$ & 32 & 26.6 \\
\hline Above 40 & 21 & $17 \cdot 5$ \\
\hline Total & 120 & 100 \\
\hline \multicolumn{3}{|l|}{ Reasons } \\
\hline Price & 42 & 35 \\
\hline Comfort & 25 & 20.83 \\
\hline Safety traits & 39 & 32.5 \\
\hline Others & 14 & 11.6 \\
\hline Total & 120 & 100 \\
\hline \multicolumn{3}{|c|}{ Frequency of use } \\
\hline Daily & 22 & 18.3 \\
\hline Weekly & 85 & 70.83 \\
\hline Once a month & 13 & 10.83 \\
\hline Total & 120 & 100 \\
\hline Reasonstouse & & \\
\hline
\end{tabular}




\begin{tabular}{|l|c|c|}
\hline Airport/Rail & 20 & 16.6 \\
\hline To and from entertainment events & 69 & 57.5 \\
\hline To and from work & 25 & 20.83 \\
\hline Others & 6 & 5 \\
\hline Total & $\mathbf{1 2 0}$ & $\mathbf{1 0 0}$ \\
\hline Timeofusage & 59 & 49.16 \\
\hline Morning/Afternoon & $\mathbf{2 8}$ & $\mathbf{2 3 . 3 3}$ \\
\hline Evening & 33 & 27.5 \\
\hline Night & $\mathbf{1 2 0}$ & $\mathbf{1 0 0}$ \\
\hline Total & & \\
\hline
\end{tabular}

\section{RANKING ANALYSIS}

\section{TABLE SHOWING THE RESPONDENTS RANKING TOWARDS DIFFICULTIES FACED FROM MOST FACTOR}

\begin{tabular}{|l|c|c|c|c|c|}
\hline \multicolumn{7}{|c|}{ Descriptive Statistics } \\
\hline Difficulties faced & N & Mean & Std. Deviation & Minimum & Maximum \\
\hline Drivers irresponsibility & 120 & 3.89 & 2.329 & 1 & 9 \\
\hline At times drivers cancel the ride & 120 & 4.58 & 2.393 & 1 & 9 \\
\hline Extra charges for cancelling & 120 & 5.53 & 2.439 & 1 & 9 \\
\hline Inexperienced drivers & 120 & 6.16 & 2.596 & 1 & 9 \\
\hline Proper time management is must & 120 & 4.35 & 2.731 & 1 & 9 \\
\hline $\begin{array}{l}\text { Alternate cabs should be specified, } \\
\text { any }\end{array}$ & 120 & 5.45 & 2.466 & 1 & 9 \\
\hline Extra charges on traffic & 120 & 5.73 & 2.383 & 1 & 9 \\
\hline Maps facilities should be trained & 120 & 4.44 & 2.428 & 1 & 9 \\
\hline Avoid phone calls while driving & 120 & 4.78 & 2.598 & 1 & 9 \\
\hline
\end{tabular}




\begin{tabular}{|l|c|c|}
\hline \multicolumn{1}{|c|}{ Difficulties faced } & Mean Rank & Ranks \\
\hline Drivers irresponsibility & 3.90 & 4 \\
\hline At times drivers cancel the ride & 4.59 & 7 \\
\hline Extra charges for cancelling & $5 \cdot 53$ & 9 \\
\hline Inexperienced drivers & 6.17 & 2 \\
\hline Proper time management is must & 4.36 & 6 \\
\hline Alternate cabs should be specified, if any & 5.46 & 8 \\
\hline Extra charges on traffic & 5.75 & 3 \\
\hline Maps facilities should be trained & 4.47 & 5 \\
\hline Avoid phone calls while driving & 4.78 & \multicolumn{2}{|c|}{} \\
\hline
\end{tabular}

A Friedman test was conducted to determine whether participants had a differential rank ordered preference for the difficulties faced from most factors. Results of that analysis indicated that there was a differential rank ordered preference for the difficulties faced from most factors, ${ }^{2}(2)=306.319$, $\mathrm{p}<.05$. A comparison of the rank ordered preferences for the difficulties faced from most factors was conducted. Results of this analysis indicated that there were significantly more favorable rankings is Drivers irresponsibility over others such as Proper time management ranks $2^{\text {nd }}$, Maps facilities should be trained $3^{\text {rd }}$, At times drivers cancel the rideranks $4^{\text {th }}$, ranks Avoid phone calls while driving $5^{\text {th }}$, Alternate cabs should be specified, if any ranks $6^{\text {th }}$, Extra charges for cancelling ranks $7^{\text {th }}$, Extra charges on traffic ranks $8^{\text {th }}$ and Inexperienced drivers ranks $9^{\text {th }}, \mathrm{p}<.05$. There was, however, no significant difference in how respondents evaluated difficulties faced from most factors.

\section{FINDINGS:}

\section{SIMPLE PERCENTAGE ANALYSIS}

1. $54 \%$ of the respondents gender are females

2. $43.33 \%$ of the respondents age group is between $21-30$

3. $35 \%$ of the respondents reason to prefer ola is price

4. $70 \%$ of the respondents frequency of use is monthly

5. $52.5 \%$ of the respondents prefer to use based on to and from entertainment events

6. $59 \%$ of the respondents time of usage is Morning/Afternoon 


\section{RANKING ANALYSIS}

- Results of ranking analysis towards difficulties faced from most factors indicated that there were significantly more favorable rankings are Drivers irresponsibility.

\section{SUGGESTIONS}

- $\quad$ To train the cab drivers with mobile application usage.

- To maintain proper time management

- If any changes in the cab number it should be specified.

- $\quad$ Provide with free calls while connecting to the driver

- Charges on tariffs should be properly fixed, especially during peak hours.

- The vehicles should be properly maintained.

- The company logo and the sticker should be visible.

- Card payments must be accessible in the near future.

- $\quad$ To increase the infrastructure of the vehicles.

- To provide with offers and discounts on festival seasons.

\section{CONCLUSION}

Ola has seen a tremendous growth in the taxi market sector. Revenue of Ola has increased almost 10 folds over the past four years. Today, it is the largest cab service provider in the country. Ola has successfully achieved public support and has created a buzz about its brand in the market. Furthermore if some more technological advancement is done at Ola then the customer base can be increased by providing better experience to the customer. Ola now has shifted its focus on target markets and is focused on providing desired service to the people in the target market. The study however concludes that, due to a large number of benefits provided to the travelers, app based taxies are being very popular day by day, not only in the metro cities of India but also in the other urban areas. However, a consistency in quality will make them able to survive in future.

So OLA has been and will be a great technology platform for transportation and offering flexible options of booking and payment to customers and flexible timings and facilities to drivers. And shortly, we are going to experience a big boom and great facility of getting our grocery delivered to us with ease.

\section{REFERENCES:}

1. Gilbert G, Samuels RE (1982) The Taxicab-An urban transportation survivor gets new cab service. Times of India.

2. Wishart D, Evenhuis A, Mangan H (2018) Road Safety Manual for the Taxi Industry.

3. Kashyap R, Bhatia A (2018) Taxi Drivers and Taxidars : A Case Study of Uber and Ola in Delhi. Journal of Developing Societies 34: 169-194. 
4. Mahapatra S, Telukoti P (2018) Challenges Faced By The Uber Drivers And Consumers Satisfaction smart City. Global Journal for Research Analysis.

5. Kashyap R, Bhatia A (2018) Taxi Drivers and Taxidars: A Case Study of Uber and Ola in Delhi. Journal of Developing Societies 34: 169-194

6. Kumar, Kishore \& Namavaram, Ramesh. (2016). A Study on Factors Influencing the Consumers in Selection of Cab Services. International Journal of Social Science and Humanities Research. Vol-4, Issue-3, ISSN 2348-3164, Pp: 557-561.

\section{BIBLIOGRAPHY}

A, R. ((2016)). Call taxi has greater value.

al, L. e. (2015). driver behavior has negative impact on the cab services at Ghana

He, G. \&. (2014), mobile apps help both drivers and passengers to find each other

Jain, H. ( 2017), states about the taxi revolution services in smart cities

Sagar, H. a. (2016), The cab services are proving security through global positioning system (GPS) and women taxi drivers for women passengers especially during night times.

Yeboah, H. a. (2015), has argued that driver behavior has negative impact on the cab services at Ghana.

\section{Annexure}

1. Name (optional)

2. Age: $\square$ o-20 $\square$ 21-30 $\square 31-40 \quad \square$ Above 40

3. Gender: Male $\square$ Female

4. What is the main reason you choose Ola services:

Price $\square \quad$ Comfort $\square \quad$ Safety traits

5. How often do you use OLA:

$$
\text { Daily } \square \text { Weekly } \square \text { Once a month }
$$

6. What purpose you use Ola often:

Airport/Rail $\square$ To and from entertainment events $\square$ To and from work

Others, specify.

7. At what time of the day do you most often require Ola services :
Morning/afternoon
Evening $\square$ Night

8. Please tick the level of satisfaction by passenger while hailing ola services:

\begin{tabular}{|l|l|l|l|l|l|}
\hline & $\begin{array}{c}\text { HIGHLY } \\
\text { SATISFIED }\end{array}$ & SATISFIED & NEUTRAL & DIS-SATISFIED & $\begin{array}{c}\text { STRONGLY DIS } \\
\text { SATISFIED }\end{array}$ \\
\hline $\begin{array}{l}\text { App based taxi/car is } \\
\text { quickly } \\
\text { Available }\end{array}$ & & & & & \\
\hline
\end{tabular}




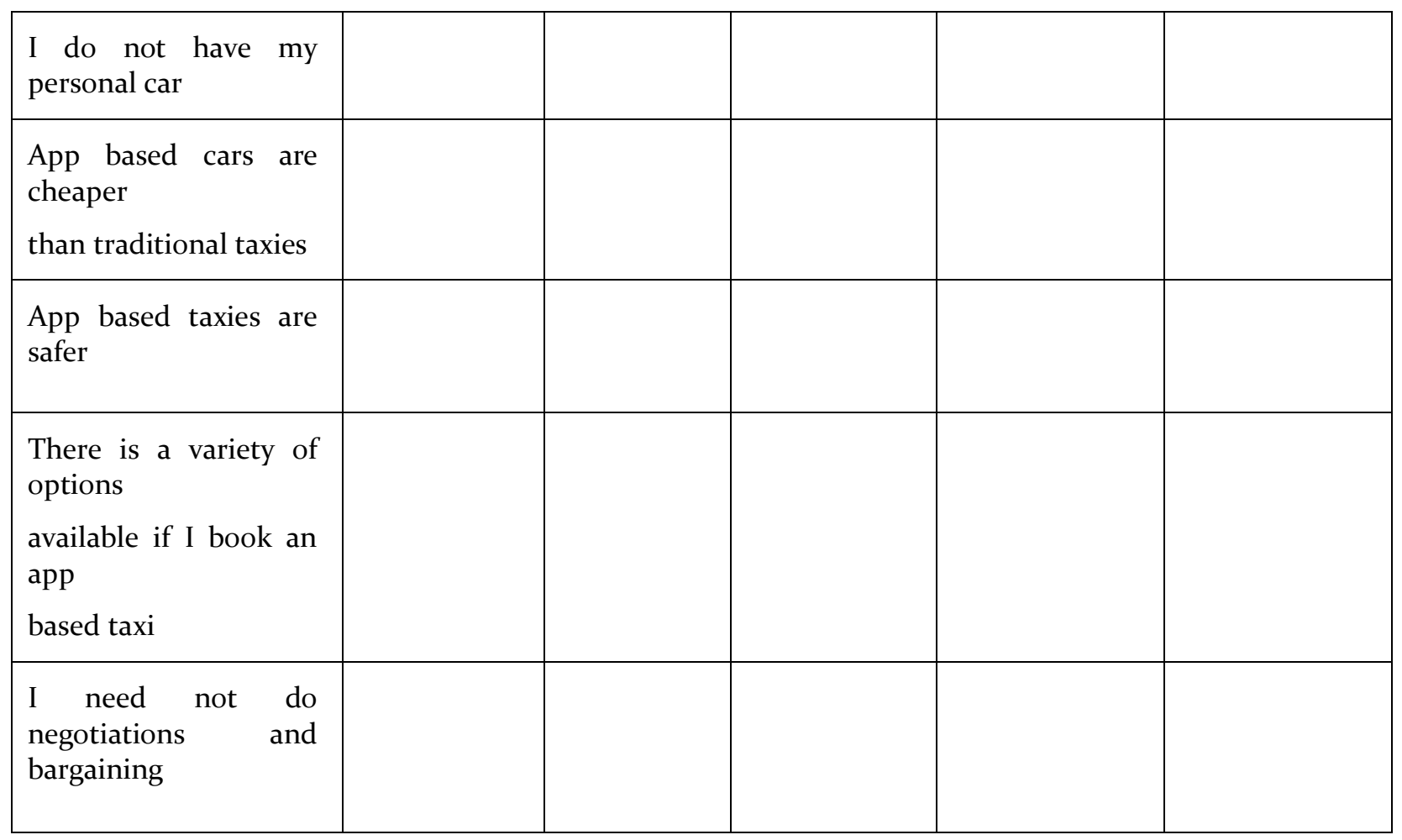

9. Rank the range of difficulty faced from most difficult to least:

\begin{tabular}{|c|l|c|}
\hline No. & \multicolumn{1}{|c|}{ DIFFICULTIES FACED } & RANKING \\
\hline 1 & Drivers lack of knowledge & \\
\hline 2 & At times drivers cancel the ride & \\
\hline 3 & Extra charges for cancelling & \\
\hline 4 & Inexperienced drivers & \\
\hline 5 & Proper time management is must & \\
\hline 6 & Alternate cabs should be specified, if any & \\
\hline 7 & Extra charges on traffic & \\
\hline 8 & Maps facilities should be trained & \\
\hline 9 & Avoid phone calls while driving & \\
\hline
\end{tabular}

